\author{
Anna Francesconi ${ }^{1}$, Gaetano \\ Paparella $^{2 \star}$, Barbara Frossi ${ }^{3}$, Elisa Del \\ Terra $^{4}$, Francesco Saverio Ambesi \\ Impiombato $^{4}$ and Francesco Curcio ${ }^{4}$ \\ ${ }^{1}$ Heart Rhythm Management Center, Vrije \\ Universiteit van Brussel, Laarbeeklaan 101, 1090, \\ Brussel, Belgium \\ ${ }^{2}$ Heart Rhythm Division, Brussel Heart Center, \\ Clinique S. Jean, Boulevard du Jardin Botanique, 32 \\ 1000, Brussel, Belgium \\ ${ }^{3}$ Department of Biomedical Sciences and \\ Technologies, Immunology Section, University of \\ Udine, P. le S. Maria della Misericordia, 1 - 33100, \\ Udine, Italy \\ ${ }^{4}$ Department of Pathology and Experimental \\ Medicine, University of Udine, P.le S. Maria della \\ Misericordia, 1-33100, Udine, Italy \\ Dates: Received: October 16, 2014; Accepted: \\ March 04, 2015; Published: March 07, 2015 \\ *Corresponding author: Gaetano Paparella, MD \\ Department of Cardiology - Brussel Heart Center - \\ Clinique S. Jean - Boulevard du Jardin Botanique, 32 \\ - 1000 - Bruxelles, Brussel - Belgium, Tel : 003202 \\ 2219111; E-mail: ga.pap@libero.it
}

www.peertechz.com

Keywords: Heart failure; Cell culture; C-kit; Differentiation

ISSN: 2455-2976

\section{Research Article \\ C-Kit Positive Cells from Failing Human Hearts: Role of Culturing Media on Cardiomyogenic Potentials}

\begin{abstract}
Background: The possibility of culturing heart cells in order to regenerate damaged tissue is a challenging problem. Recent observations have demonstrated the possibility of isolating and expanding resident cardiac stem cells, which could favor regeneration and functional improvement of the myocardial tissue.

Aims: To investigate two different culturing media: one promoting c-kit cells' growth and the other promoting differentiation in cardiac muscle cells.

Methods: We obtained primary cultures from left ventricle myocardial tissues of 10 human hearts of patients with end-stage heart failure who received heart transplantation. Cells were first cultured in a medium containing high serum and low calcium/magnesium $\left(\mathrm{Ca}^{2+} / \mathrm{Mg}^{2+}\right)$ to promote cell growth (medium A). Than they were cultured in another medium that contained lower serum concentration and a variety of different factors in order to induce cell differentiation (medium B). The presence of c-kit, specific for stem cells, $\alpha$-sarcomeric actin (SA), specific for skeletal and cardiac muscle cells, and a-smooth muscle actin (SMA), specific for smooth muscle cells was studied by immune-cytochemical analysis.
\end{abstract}

Results: A high percentage of c-kit+, SMA-, SA- cells was observed in medium A; in medium B with lower serum and higher $\mathrm{Ca}^{2+} / \mathrm{Mg}^{2+}$ concentrations cells became $\mathrm{c}-\mathrm{kit}-, \mathrm{AML}+, \mathrm{SA}+$.

In medium A, $78 \%$ of the cells were positive for c-kit. After culturing the same cell populations in medium $B$ with lower serum and higher $\mathrm{Ca}^{2+} / \mathrm{Mg}^{2+}$ concentrations, the percentage of c-kit positive cells decreased to $21 \%$ while the cells positive for SMA and for SA increased respectively from 28 to $82 \%$ and from 0 to $59 \%$.

Conclusions: Our results confirm the presence of a high percentage of c-kit positive cells in failing human myocardium and, for the first time, suggest a key role of calcium/magnesium concentration in promoting both c-kit cells' growth and their differentiation in human cardiac muscle.

\section{Introduction}

Culturing heart cells is still a challenging problem due to the absence of suitable cell lines enabling easy gene expression manipulation and notion [1]. In the last decade many groups have been culturing human heart cells with the intent of reproducing feasible myocardial tissue. The possibility of culturing stem cells has given a great impulse to this attempt and many advances have been made in two main directions: culturing embryonic $[2,3]$ and adult stem cells.

Adult-derived cardiomyocytes have been obtained from extracardiac stem cells found in peripheral tissues such as bone marrow [4,5], whole blood [6] and muscle tissue [7]. Progresses have been made also in the sense of in vivo engraftment of the obtained differentiated cells into myocardial tissue $[8,9]$ despite difficulties in making functional engraftments.

It has been recently demonstrated that cardiac-stem cells could be "circulating" cells similar to those found in extra-cardiac tissue [10], as well as local "residential" cells constitutionally present [11-13].

Messina and coworkers have identified multipotent cells in adult human heart tissue and successfully expanded them in culture as cardiospheres (CS) [14]. They have also obtained cell differentiation of the Cardiospheres Derived Cells (CDC) and in-vivo engraftment in post-infarcted tissue [15]. These results seem to give a great opportunity for making autologous transplants in patients with reduced functional myocardial tissue.

Although this last possibility seems very promising there are some difficulties in culturing differentiated cells. In the mentioned experiments, co-cultures with mouse myocytes seemed to give the right commitment to undifferentiated cells to become differentiated myocytes. The latter were characterized by autonomous electrical capacity and successful engraftment both morphological and functional [15].

Aiming to develop differentiated myocytes we have cultured human myocardial tissue using two media: one to promote cell growth rather than cell differentiation using high serum concentration and low $\mathrm{Ca}^{2+} / \mathrm{Mg}^{2+}$ (medium A) and the other to promote cell differentiation using a medium with lower serum concentration and high $\mathrm{Ca}^{2+} / \mathrm{Mg}^{2+}$ (medium B). 
Three markers were used to identify different cells lineages: c-kit, which is the receptor for stem-cell factor [16], $\alpha$-sarcomeric actin (SA), specific for skeletal and cardiac muscle cells [17,18], and -smooth muscle actin (SMA), specific for smooth muscle cells $[5,19]$.

\section{Aims}

We sought to investigate two different culturing media in order to promote c-kit cells' growth and to enable their differentiation in human cardiac cells.

\section{Methods}

\section{Patients}

Samples of human myocardium $(1 \mathrm{~cm} \mathrm{x} 1 \mathrm{~cm} \times 1 \mathrm{~cm})$ were obtained from 10 patients suffering from non-ischemic cardiomyopathy with indication to heart transplantation. Seven patients were men, the mean age was $55 \pm 9$ years. Samples of tissue were taken from free wall of left ventricle and they were stored in proliferation medium in order to ensure cells' viability. Thus samples were processed from 1 up to 8 hours after heart explantation. Informed consent for using discarded hearts was obtained from the patient.

\section{Cell cultures}

Where not specified, reagents were from Sigma Aldrich (Sigma, St. Louis, MO).

Primary cultures: The fragment of tissue was minced and incubated for two hours at $37^{\circ} \mathrm{C}$ in $20 \mathrm{U} / \mathrm{ml}$ collagenase, $512 \mathrm{mU} / \mathrm{ml}$ trypsin, $2 \%$ dialyzed and heat inactivated chicken serum, $\mathrm{Ca}^{2+}$ and $\mathrm{Mg}^{2+}$ free Hanks' solution (CTC mixture) with $20 \mathrm{U} / \mathrm{ml}$ collagenase Type 2 and $5 \mathrm{U} / \mathrm{ml}$ DNAse. The remaining pieces of tissue were positioned under $1 \mathrm{~cm}^{2}$ microscope slides cover glasses into culture dishes (Becton Dickinson, Franklin Lakes, NJ) and cultured at $37^{\circ} \mathrm{C}$, $5 \% \mathrm{CO}_{2}$ with $10 \mathrm{ml}$ of medium $\mathrm{A}$.

Medium A: To promote cell growth we used our previously described medium [20] enriched by high serum (5\%) and low calcium/ magnesium $(0,33 \mathrm{mM} \mathrm{Ca} 2+/ 0,15 \mathrm{mM} \mathrm{Mg} 2+)$ concentrations. Thus we added $50 \mathrm{ng} / \mathrm{ml}$ of adrenomedulline and $5 \mathrm{mU} / \mathrm{ml}$ erythropoietin because of their well-known proliferation properties. Medium was changed twice a week and cells were split at $80 \%$ confluence using CTC and plated at 400,000 cells/dish. Once detached from the tissue fragments cells were split and plated on coverglasses. Cells proliferated forming clusters. After 8 days of culture in medium A part of the cells were fixed for immune-cytochemical analysis and part of the cells were cultured in medium B. At each passage cells were frozen in liquid nitrogen in medium A with 10\% DMSO.

Medium B: To promote cell differentiation, fetal calf serum (FCS) concentration was lowered to $2 \%$ instead of $5 \%$ and different parameters were changed one at a time: $\mathrm{Ca}^{2+} / \mathrm{Mg}^{2+}$ concentration was raised to $2.2 \mathrm{mM} \mathrm{Ca}^{2+} / 1 \mathrm{mM} \mathrm{Mg}^{2+}$ or to $6.6 \mathrm{mM} \mathrm{Ca}^{2+} / 1 \mathrm{mM}$ $\mathrm{Mg}^{2+}$; insulin concentration was raised to $20 \mu \mathrm{mg} / \mathrm{ml} ; 25 \mathrm{ng} / \mathrm{ml}$ Amphotericine B was added; $0.1 \mathrm{mM}$ growth stimulating hormone (GSH) was added; $25 \mu \mathrm{g} / \mathrm{ml}$ heart extract was added to the medium. After 8 days of culture in medium B the cells were fixed for immunecytochemical analysis.
Extracts: Freshly frozen bovine hypothalamus, bovine pituitary (Pel-Freez Biological, Rogers, AK) and human heart were prepared as described by Curcio et al. [20]. Protein concentration was determined using BCA-Protein Assay Kit (Pierce, Rockland, IL) and the extracts were added to a final concentration of $75 \mathrm{mg} / \mathrm{ml}, 50 \mu \mathrm{mg} / \mathrm{ml}$ and 25 $\mu \mathrm{g} / \mathrm{ml}$ respectively.

\section{Confocal microscopy and immunocytochemical analysis}

For immunocytochemical studies cells were thawed, plated on coverglasses, cultured for 8 days and then fixed in a $4 \%$ paraformaldehyde. Afterwards they were washed and treated with phosphate-buffered saline (PBS) solution containing $0.1 \%$ Triton $\mathrm{X}-100$, then incubated overnight at $4^{\circ} \mathrm{C}$ with mouse monoclonal $\alpha$-SA antibody (1:2000 in PBS buffer with $450 \mathrm{mM} \mathrm{NaCl}$ ), and $\alpha$-SMA antibody (1:50; Dako, Carpinteria, California) to identify muscle cells and rabbit polyclonal anti-c-kit antibody, CD117 (1:25; Dako) and mouse monoclonal CD34 antibody (1:20; Immunotech Coultard, Marseille, France) to identify primitive cells $[5,13]$.

Goat anti-mouse IgG or goat anti-rabbit IgG conjugated with Fluoroisothiocyanate (FITC-Vector lab, Burlingame, California) were used as secondary antibodies. For double staining the same procedure was repeated twice and the secondary antibodies, specific for each primary antibody, were labeled with: Fluoroisothiocyanate (FITC-Vector) or Tetramethyl Rhodamine Isothiocyanate (TRICVector) respectively. Blocking was performed using the Avidin/ Biotin blocking kit (Vector). Cells were then processed for confocal microscopy as described by Longin et al. [21]. And examined using Zeiss Axiophot Photomicroscope equipped with Epifluorescence (C.F. Zeiss, Oberkochen, West Germany) or using Leica DMRE confocal laser scanning microscope (Leica, TCS-NT) with a 40x or 63x oil-immersion objective lens of numerical aperture 1 . The excitation wavelengths used were $488 \mathrm{~nm}$ (FITC) and $568 \mathrm{~nm}$ (TRIC). Filters used for collecting emission signals were 522/35 nm (FITC) and $>632$ $\mathrm{nm}$ (TRIC).

We used the secondary antibody as negative controls. In addition we also used the following cellular controls, both positive and negative:

a) Endothelial primary cultures, obtained from the aortic arch of the same patients. Primary cultures were obtained and cells were cultured as described by Donnini et al. [22]. Only cultures positive for CD31 expression by cytofluorimetric analysis were used. CD31 positive cells were utilised as positive controls for anti c-kit antibody and as negative controls for anti-SA and anti-SMA expression.

b) H9c2 cells (CRL-1446; American Type Culture Collection of Rockville, MD, USA) are a clonal cell line of mononucleated myoblasts derived from embryonic BDIX rat heart tissue [23]. We cultured H9c2 cells in Dulbecco's Modified Eagle's Medium (Euroclone, West Yorks, UK) with $4 \mathrm{mM}$ glutamine and serum concentration of 10 or $1 \%$. After 8 days they were tested with anti-SA and anti-SMA antibodies.

c) $\mathrm{H} 5 \mathrm{~V}$ cells are endothelial cells derived from the heart of C57BL/6 mice [24]. They were cultured in Dulbecco's Modified Eagle's Medium (Euroclone) with 10\% FCS and they were used as positive controls for CD31 molecule for cytofluorimetric analysis. 


\section{Flow cytometry}

CD31 expression was studied by flow cytometry. Cells were resuspended at 1,000,000 cells $/ \mathrm{ml}$ and fixed in $4 \%$ paraformaldehyde. Afterwards cells were incubated for 1 hour at $37^{\circ} \mathrm{C}$ with the antiCD31 mouse monoclonal antibody (1:20; Dako). Cells were then incubated for 1 hour with goat anti-mouse IgG antibody conjugated with Fluoroisothiocyanate (FITC-Vector). Analysis was performed with FACStar cytofluorimeter (Becton Dickinson, San Jose, CA).

\section{Statistical analysis}

Evaluation of positive cells was done by counting 50 cells in 5 different fields and dividing the number of positive cells by the total number of cells. Counting was performed by two independent operators. Results are presented as means $\pm \mathrm{SD}$.

\section{Results}

Samples of left ventricle myocardium were taken from the explanted hearts of 10 patients with end-stage heart failure undergoing heart transplantation.
Medium A, containing high serum (5\%) and low calcium/ magnesium $(0,33 \mathrm{mM} \mathrm{Ca} 2+/ 0,15 \mathrm{mM} \mathrm{Mg} 2+)$ concentrations, was used to promote cell proliferation. We obtained growing cells in eight primary cultures. Cells proliferated and formed clusters and after 8 days of culture in the same medium, were fixed for immunocytochemical analysis. We found that $78 \pm 13 \%$ of the cells were positive for c-kit, $28 \pm 7 \%$ of the cells resulted positive for SMA whereas there were no positive cells for SA (Figures 1A-G). SMA appeared to be organized in filamentous structures (Figure 1E), which is normally indicative of a greater differentiation, being the polymer the functional form of actin in cells. C-kit positive cells were also tested for the presence of CD34 and CD31. Immunocytochemical analysis revealed that c-kit positive cells were negative for CD34 that is a marker of hematopoietic cells. The cytofluorimetric analysis revealed that cells were negative also for CD31, a marker of endothelial cells. The presence of c-kit positive cells confirmed that undifferentiated cells were present in adult failing human heart, either as circulating or residential cells. Once cultured in medium A, these cells were able to proliferate in vitro.

To promote differentiation of cells cultured in medium a, they

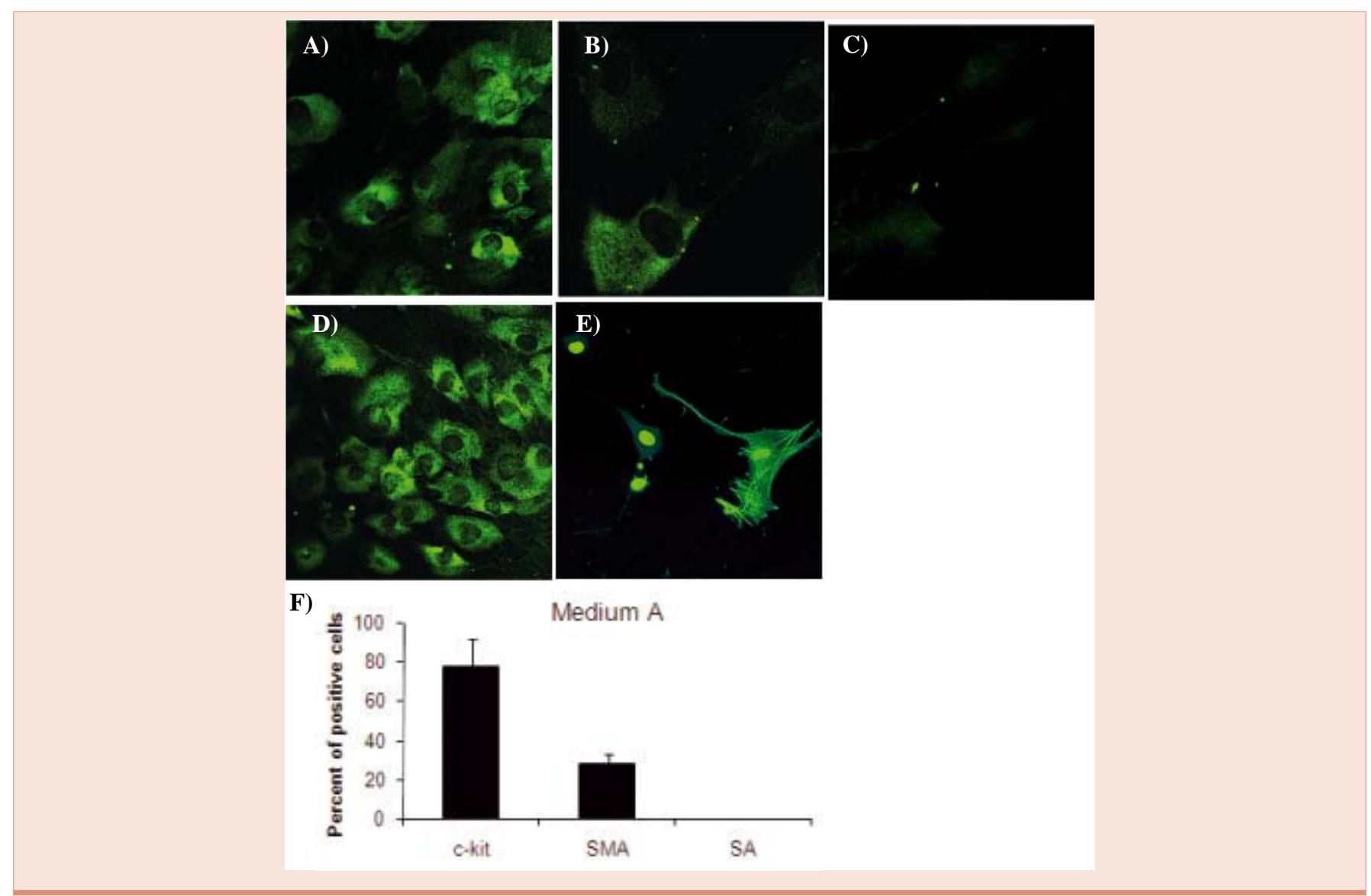

Figure 1: C-kit, SMA and SA Labeling of Cells from Left Ventricle and Aortic Arch of Failing Hearts, Cultured in Medium A. In Panels A, B, C and D, green fluorescence indicates localization of c-kit molecule on cells derived from human myocardium. Panel A shows c-kit positive cells in primary cultures at the first passage ( $\mathrm{p} 0$ ). Panel B shows a c-kit positive cell with two negative cells utilized as internal negative controls. Panel $\mathrm{C}$ shows negative controls obtained incubating cells with secondary antibody and non-immune serum instead of primary antibody. Panel D showsendothelial cells obtained from aortic arch of the explanted failing hearts used as positive controls for the c-kit molecule. In Panel E, green fluorescence indicates localization of SMA. Nuclei where counterstained with propidium iodide. There are two SMA-negative cells utilized as internal negative controls. The scale bars represent $10 \mu \mathrm{m}$. Unstained central areas correspond to cell nuclei. 
were subsequently cultured for 8 days in medium B in which FCS concentration was reduced from 5 to $2 \%$, and one at a time different solutes were added. No SA positive cells were found with $2.2 \mathrm{mM}$ $\mathrm{Ca}^{2+} / 1 \mathrm{mM} \mathrm{Mg}^{2+}$, insulin $20 \mu \mu \mathrm{g} / \mathrm{ml}$, Amphotericine B $25 \mathrm{ng} / \mathrm{m}$, GSH $0.1 \mathrm{mM}$ or heart extract $25 \mu \mu \mathrm{g} / \mathrm{ml}$ in the medium. SA positive cells were found only in medium $\mathrm{B}$ with $\mathrm{Ca}^{2+} / \mathrm{Mg}^{2+}$ concentration of $6.6 \mathrm{mM} / 1 \mathrm{mM}$, (Figure $2 \mathrm{~A}$ ). In the latter, c-kit+ cells decreased to $21 \pm 7 \%$, SMA+ cells increased to $82 \pm 18 \%$ and there were $59 \pm 8 \% \mathrm{SA}+$ cells (Figure 2B).

After 8 days in Medium B double staining of cells with anti-ckit and anti-SMA antibodies showed that the expression of c-kit molecule was inversely related to the expression of SMA (Figures 3A-D) suggesting successive stages of differentiation. Two main cells populations were identified: those which changed phenotype becoming c-kit-/SMA+ and those which did not change phenotype remaining c-kit+/SMA-. Double staining for SMA and SA showed that $44 \pm 15 \%$ of the cells were SMA+/SA- (Figures $4 \mathrm{~A}, 4 \mathrm{~B}$ ), $22 \pm 3 \%$ were SMA-/SA+(Figures $4 \mathrm{C}, 4 \mathrm{D}$ ) whereas $34 \pm 13 \%$ of the cells were double positive SMA+/SA+ (Figures 4E, 4F).

$\mathrm{H} 9 \mathrm{c} 2$ cells were used as controls for SA. These cells are a clonal line of mononucleated myoblasts that remain undifferentiated in $10 \%$ serum and differentiate into skeletal muscle cells with $1 \%$ serum concentration. Therefore H9c2 were cultured under both conditions and tested for both SA and SMA. When cultured in $10 \%$ FCS, $3 \pm 1 \%$ of the cells was positive for both antibodies while the other $97 \pm 1 \%$ of the cells was positive only for SMA (Figures $5 \mathrm{~A}-\mathrm{C}$ ). With $1 \%$ FCS, cells started to form multinucleated structure and $45 \pm 5 \%$ were positive for
SA (Figures 5E-F). Double staining for SA and SMA demonstrated that positive cells for SA remained positive for SMA as well.

Endothelial cells were used as positive controls for the c-kit molecule. This line was obtained from the aortic endothelium of the explanted hearts as described by Donnini et al. [22, 25]. The cells were always positive for the c-kit molecule (Figure 1D). They were also used as negative controls for SMA (Figure 1F) and SA (Figure 5D). Cells used tested positive for $\mathrm{CD} 31$ expression by cytofluorimetric analysis. For the analysis H5V cells were also used. These are endothelial cells derived from the heart of C57BL/6 mice [24] and they were used as positive controls for CD31.

\section{Discussion}

Our study demonstrates that c-kit positive cells are present in failing human heart and they can be isolated and cultured in vitro. Proliferating c-kit positive cells detached from tissue sample as previously described by other groups [15]. Different cell types were identified in culture by immunocytochemical analysis: smaller c-kit+ cells, bigger and flattened SMA+ cells.

\section{C-kit positive cells}

The percentage of c-kit positive cells in our cultures was unusually high. This could be due to culturing conditions, which positively selected them, or to their presence in high percentage in failing heart, as recently demonstrated by Kubo and coworkers [26]. The presence of negative cells in the same culture (Figure 1B) confirmed that the high percentage of c-kit positive cells was not due to a non-specific binding of the antibody. The c-kit molecule is the receptor for stem

A

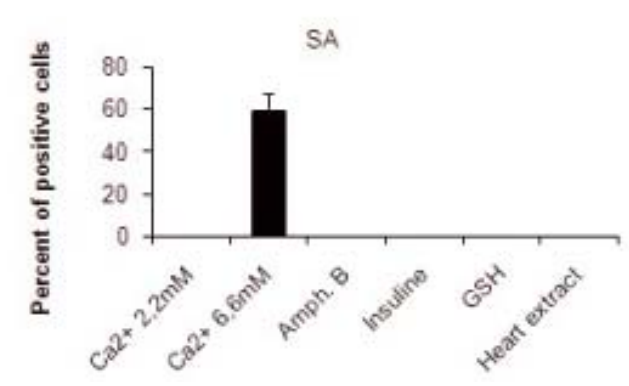

B

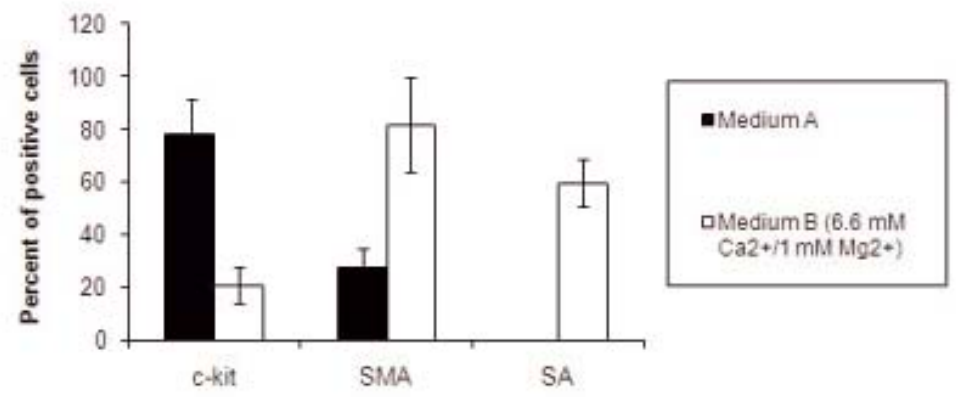

Figure 2: Number of Cells Expressing c-kit, SMA and SA in Cultures from Left Ventricle of Failing Hearts in Medium B. Panel A represents cells cultured in medium $B$ and tested for SA. Cells positive for SA $(60 \pm 6 \%)$ were present only in medium with $\mathrm{Ca}^{2+} / \mathrm{Mg}^{2+} 6.6 \mathrm{mM} / 1 \mathrm{mM}$. In all other conditions there were no positive cells for SA. H9c2 cells resulted positive for the same molecule.Panel $B$ represents the effect of medium $A$ and medium $B$ with Ca ${ }^{2+} / \mathrm{Mg}^{2+} 6.6$ mM/1mM, on the mean $( \pm S D)$ number of c-kit, SMA and SA positive cells. 
cell factor and it is found in hematopoietic pluripotent cells [16,25] However, it is also found in other cell types [27]. Endothelial cells derived from aortic arch were also positive for c-kit.

Our results do not explain whether c-kit+ cells present in human myocardium were derived from the walls of the cardiac vessels or they were associated to muscle tissue. De Angelis et al. suggest that satellite cells are derived from endothelial precursors associated with the embryonic vasculature. Consequently, putative vasculatureassociated precursors may continue to give rise to pluripotent stem cells in adult muscle [28] and give every organ the capacity to repair tissue damage by self-regeneration. It has been shown that heart cells have the ability of replicating after myocardial infarction [18]. This capability may be due to undifferentiated c-kit positive cells, which are able to replicate "in situ" giving rise to differentiated cells [29]. However, recent results suggest that defective cardiac progenitor cells might be a common denominator in the pathogenesis of heart failure of different etiology [30]. Thus, our findings support the advantage of improving the efficacy of endogenous undifferentiated cells rather than exogenous cell delivery for promoting cardiac regeneration.

\section{Primary cultures and Media}

Medium conditions remain crucial for cell proliferation and differentiation. Our study confirms the importance of serum concentration in inducing myocytes growth and/or differentiation
$[31,32]$ and, for the first time, outlines the role of high $\mathrm{Ca}^{2+} / \mathrm{Mg}^{2+}$ concentrations in promoting cell differentiation. Lowering serum and rising $\mathrm{Ca}^{2+} / \mathrm{Mg}^{2+}$ concentrations, some cells started to lose their c-kit phenotype and to express SMA and SA. At $2.2 \mathrm{mM} / 1 \mathrm{mM} \mathrm{Ca}^{2+} / \mathrm{Mg}^{2+}$ concentrations we did not obtain SA+ cells. They were only present when $\mathrm{Ca}^{2+} / \mathrm{Mg}^{2+}$ was raised to $6.6 \mathrm{mM} / 1 \mathrm{mM}$. Our cardiomyocytes were not homogeneous, therefore it is impossible to state that the same cells which were c-kit positive differentiated into muscle cells expressing specific actins. We speculate that a certain level of $\mathrm{Ca}^{2+} / \mathrm{Mg}^{2+}$ is necessary to promote ions influx in the cell which is responsible for cell differentiation through a mechanism similar to that obtained by electrical pacing [33] and mechanical stretching [34]. Molecules such as TRPM7, SRF, $\mathrm{Ca}^{2+} / \mathrm{Mg}^{2+}$ could likely be involved and represent a merging point for the effect of serum, calcium and magnesium on cell growth.

\section{Cells' differentiation}

Interestingly, not all the cells changed their phenotype, indicating the presence of two main cell populations as also described by Smith and coworkers. They demonstrated, by cytofluorimetric analysis, that CDCs c-kit+ cells were present in culture with CD90+ and CD31+ subpopulations [15]. We noticed that some cells did not acquire the differentiated phenotype, which supports the idea that there might be different cellular types that provide physical cell-to-cell contact (Figure 3 ) or a secreting support to the expanding cell population, as

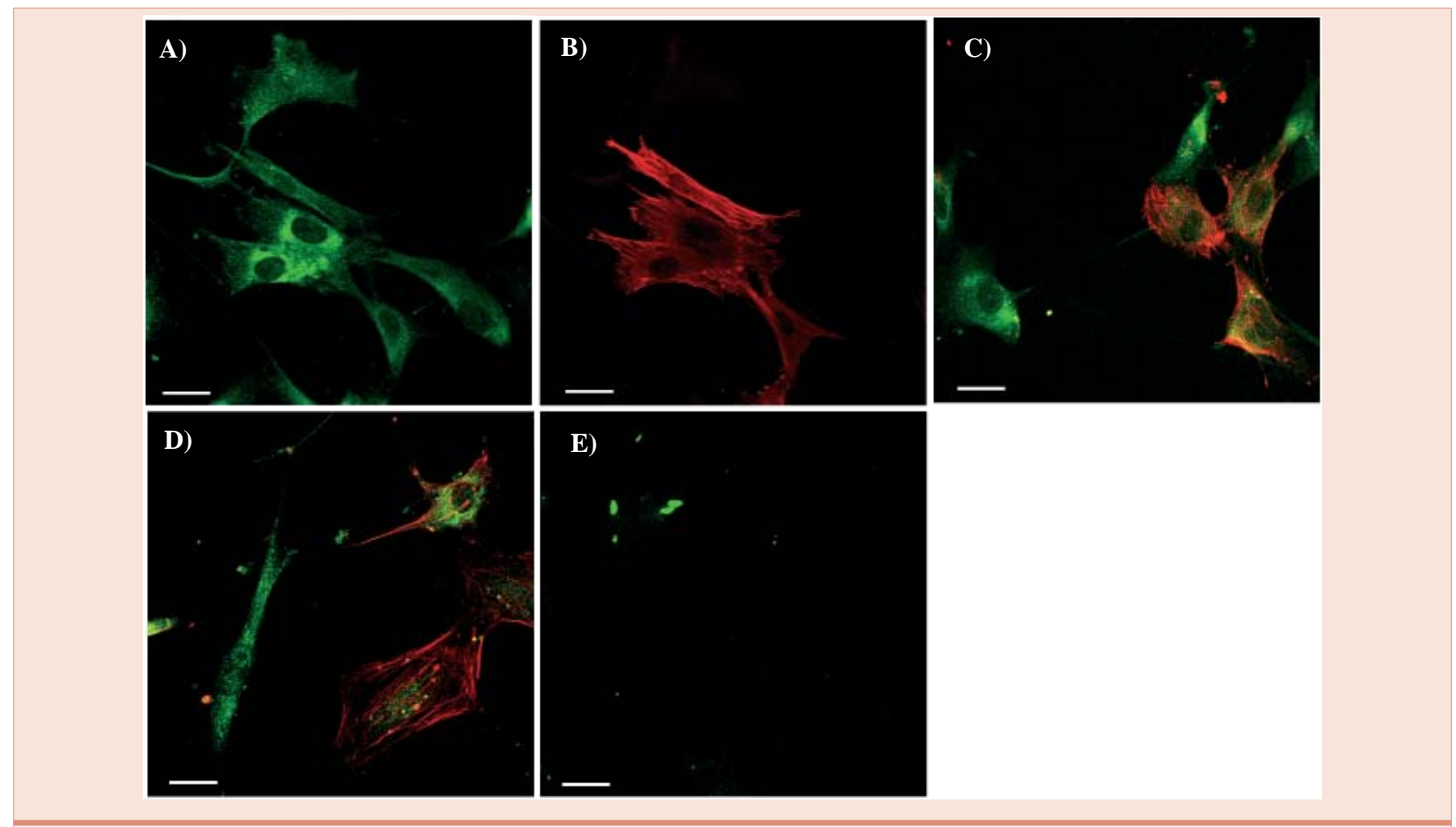

Figure 3: C-kit and SMA Labeling of Cells from Left Ventricle of Failing Hearts Cultured in Medium $B\left(\mathrm{Ca}^{2+} / \mathrm{Mg}^{2+}\right.$ was $\left.6.6 \mathrm{mM} / 1 \mathrm{mM}\right)$. In Panels $A$ to $D$ green fluorescence shows localization of c-kit, red fluorescence shows localization of SMA. For two-color fluorescence the red and green signals were collected simultaneously using Leica TCS scanning system. To create a two-color image, the red and green images were merged. Co-localization appears as yellow as result of the mixture of red and green. Panel E shows negative controls obtained incubating cells with serum instead of both primary antibodies. The scale bars represent $10 \mu \mathrm{m}$. unstained central areas correspond to cell nuclei. 

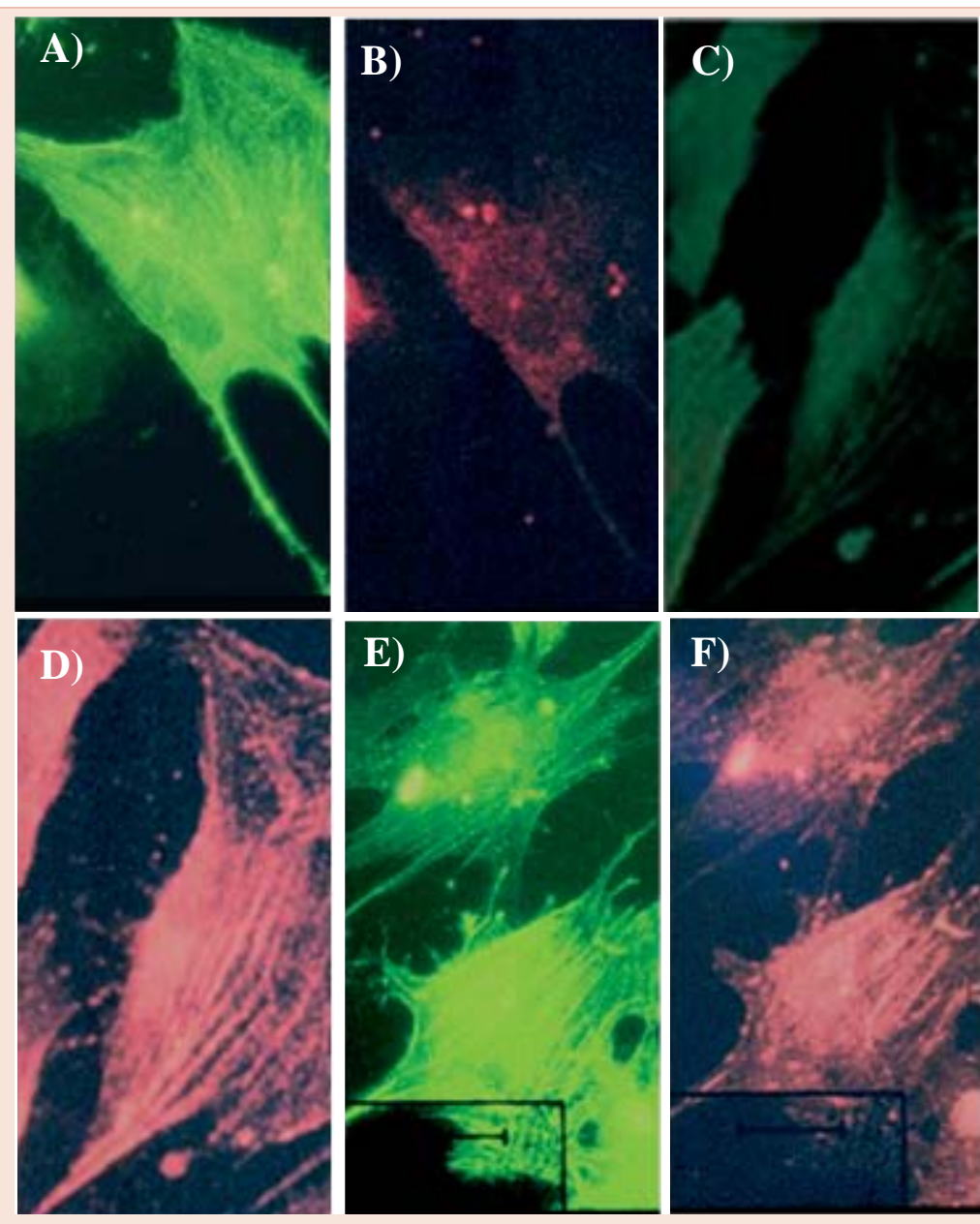

Figure 4: SMA and SA Labeling of Cells from Left Ventricle of Failing Hearts Cultured in Medium $\mathrm{B}$ with $\mathrm{Ca}^{2+} / \mathrm{Mg}^{2+} 6.6 \mathrm{mM} / 1 \mathrm{mM}^{2}$. Cells were double stained with antibody anti-SMA (green fluorescence in Panels A, C and E) and antibody anti-SA (red fluorescence in Panels B, D and F). Cells were observed with fluorescent microscope using two different filters. Panels $A$ and $B$ represents a cell positive for SMA only. Panels $C$ and $D$ represent a cell positive for SA only. Panels $E$ and $F$ represent cells double positive for both molecules. The scale bars (white lines) represent 10 $\mu \mathrm{m}$.

already hypothesized by other groups [31,35]. Our results show that the c-kit positive cells differentiated initially into smooth muscle cells and subsequently into skeletal or cardiac myocytes.

This is consistent with previous studies demonstrating that linec-kit+ cells injected into infarcted hearts are able to differentiate into myocytes, endothelial cells and smooth muscle cells [5]. Previous studies have also demonstrated that, during cardiomyogenesis, smooth muscle and striated $\alpha$-actin genes are co-expressed within myogenic cells [19]. In some cases, it was unclear whether the presence of SMA was a sign of differentiation or dedifferentiation. In fact, adult cardiomyocytes, which dedifferentiated once in culture, re-expressed SMA while SA expression remained stable throughout the culture $[19,36]$. In our experiments, the hypothesis of dedifferentiation seems incorrect since the expression of SMA did not always coincide with the expression of SA. In addition, c-kit expression decreased as cells became positive for $\alpha$-actins, a possible indication of progressive differentiation. Data from H9c2 cells were consistent with those on myocardial primary cultures. H9c2 cells in $10 \%$ serum were mainly positive for SMA and negative for SA, confirming that undifferentiated muscle cells express SMA. In $1 \%$ serum, which promotes cell differentiation, cells became positive for both SMA and SA. The expression of SA together with myotubes formation confirmed cell differentiation.

\section{Limitations}

We acknowledge that the percentage of c-kit positive cells in our cultures was unusually high. This could be due to culturing conditions which positively selected and expanded them or to their presence in high percentage in failing human heart, as recently demonstrated by Kubo et al. in sample of non-human heart [37].

In our experiments we used only one time point of staining. Unfortunately no others time points were available mostly because of the insufficient number of samples. We acknowledge that multiple time points of staining would have given a stronger accuracy of cells' differentiation.

We know that in our experiments we tested an exiguous number 

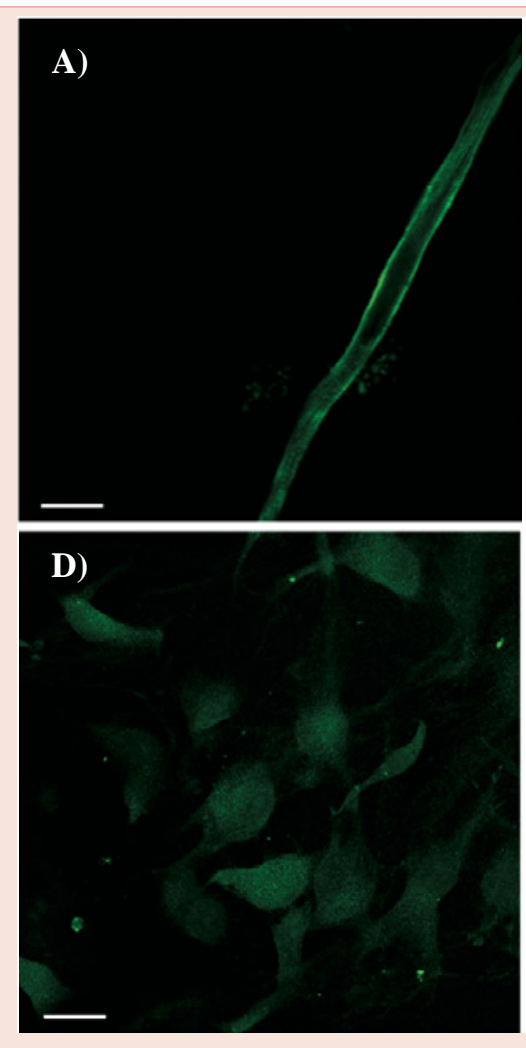

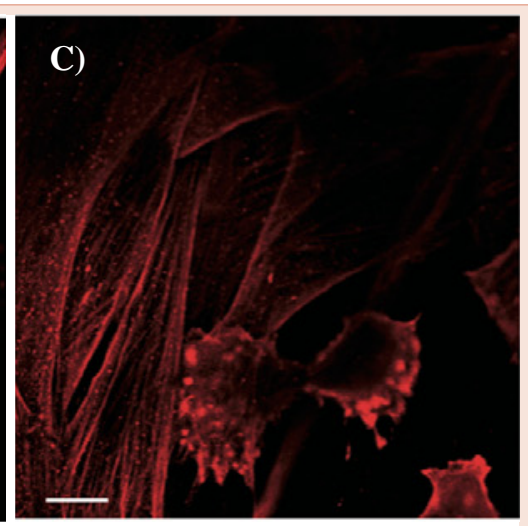

F)



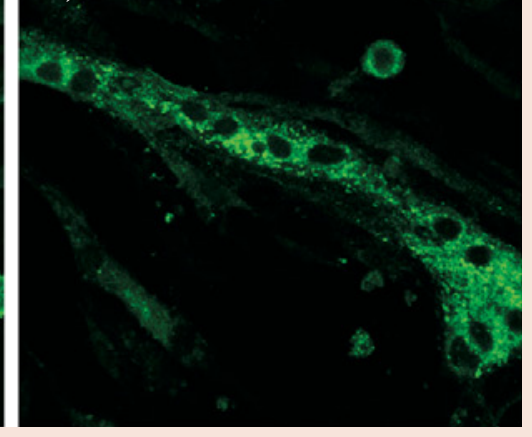

Figure 5: SMA and SA labeling of H9c2 cells, used as positive controls for antibody anti-SA, cultured in Dulbecco's Modified Eagle's Medium with 10 and $1 \%$ FCS. H9c2 cells were double stained with antibody anti-SMA (red fluorescence) and anti-SA (green fluorescence). Panels A, B and C show H9c2 cells cultured in Dulbecco's Modified Eagle's Medium with 10\% FCS. Panels B and C show SMA positive cells at two different focal plans. Panels E and F show H9c2 cultured in Dulbecco's Modified Eagle's Medium with 1\% FCS in order to promote cell differentiation. After 8 days of culture mononucleated myoblasts became multinucleated cells positive for SA (Panel E) and form myotubes like structures (Panel F). Panel D represents aortic endothelial cells used as negative controls since they were always negative for SMA and SA molecules. The scale bars represent $10 \mu \mathrm{m}$. Unstained areas correspond to cell nuclei.

of antibodies but we retain that this lack was compensated by using some cellular lines $(\mathrm{H} 9 \mathrm{c} 2, \mathrm{H} 5 \mathrm{~V})$ as positive or negative controls, according to the protocol of our study.

\section{Conclusions}

Our study demonstrates the presence of a high percentage of proliferating c-kit+ cells in failing human heart and outlines the importance of serum and $\mathrm{Ca}^{2+} / \mathrm{Mg}^{2+}$ concentrations for human cardiomyocytes differentiation process in vitro. We identified media conditions which induce cells to lose their c-kit phenotype and to acquire SA/SMA phenotype.

Our data could add important information for enhancing endogenous myocytes differentiation and repair mechanisms. It represents a well defined in vitro model for further studies in order to understand important mechanisms for promoting human cardiac regeneration.

\section{Acknowledgments}

We thank Dr. Huber and Dr. Diviacco for providing us with the H9c2 and H5V cells. We thank Prof. Brugada, Prof. Pucillo, Prof. Dobrina and Dr. Di Rosa for their excellent and helpful comments on the manuscript.

\section{Disclosure statement}

The study was partially supported by grants from ESA (European Space Agency), MAP project N. AO-99-003. None of the authors had a financial relationship with a commercial entity that had an interest in the subject of the presented manuscript or other conflicts of interest to disclose.

\section{References}

1. Germani A, Di RG, Limana F, Martelli F (2007) Capogrossi MC. Molecular mechanisms of cardiomyocyte regeneration and therapeutic outlook. Trends Mol Med 13: 125-133.

2. Tomita $Y$, Matsumura K, Wakamatsu $Y$ (2005) Cardiac neural crest cells contribute to the dormant multipotent stem cell in the mammalian heart. J Cell Biol 170: 1135-1146.

3. Fukuda K (2005) Progress in myocardial regeneration and cell transplantation. Circ J 69: 1431-1446.

4. Ferrari G, Cusella-De AG, Coletta M (1998) Muscle regeneration by bone marrow-derived myogenic progenitors. Science 279: 1528-1530.

5. Orlic D, Kajstura J, Chimenti S (2001) Bone marrow cells regenerate infarcted myocardium. Nature 410: 701-705.

6. Asahara T, Murohara T, Sullivan A (1997) Isolation of putative progenitor endothelial cells for angiogenesis. Science 275: 964-967. 
7. Menasche P (2008) Skeletal myoblasts and cardiac repair. J Mol Cell Cardiol 45: $545-553$

8. Wojakowski W, Kazmierski M, Korzeniowska B (2007) Link between erythropoietin release and mobilization of endothelial progenitor cells in acute myocardial infarction. Eur Heart J 28: 1785-1786.

9. Menasche P, Alfieri O, Janssens S (2008) Autologous Grafting in Ischemic Cardiomyopathy (MAGIC) trial: first randomized placebo-controlled study of myoblast transplantation. Circulation 117: 1189-1200.

10. Dawn B, Guo Y, Rezazadeh A (2006) Postinfarct cytokine therapy regenerates cardiac tissue and improves left ventricular function. Circ Res 98: 1098-1105.

11. Beltrami AP, Barlucchi L, Torella D (2003) Adult cardiac stem cells are multipotent and support myocardial regeneration. Cell 114: 763-776.

12. Kajstura J, Urbanek K, Rota M (2008) Cardiac stem cells and myocardia disease. J Mol Cell Cardiol;45:505-513.

13. Bearzi C, Rota M, Hosoda $T$ (2007) Human cardiac stem cells. ProcNatIAcadSci U S A104:14068-14073.

14. Messina E, De AL, Frati G (2004) Isolation and expansion of adult cardiac stem cells from human and murine heart. Circ Res 95: 911-921.

15. Smith RR, Barile L, Cho HC (2007) Regenerative potential of cardiospherederived cells expanded from percutaneous endomyocardial biopsy specimens. Circulation 115: 896-908.

16. Christensen JL, Weissman IL (2001) Flk-2 is a marker in hematopoietic stem cell differentiation: a simple method to isolate long-term stem cells. ProcNatlAcadSci U S A 98: 14541-14546.

17. Kablar B, Tajbakhsh S, Rudnicki MA (2000) Transdifferentiation of esophageal smooth to skeletal muscle is myogenic bHLH factor-dependent. Development 127: $1627-1639$

18. Beltrami AP, Urbanek K, Kajstura J (2001) Evidence that human cardiac myocytes divide after myocardial infarction. N Engl J Med 344: 1750-1757.

19. Khaitlina SY (2001) Functional specificity of actin isoforms. Int Rev Cytol 202: 35-98

20. Curcio F, Ambesi-Impiombato FS, Perrella G (1994) Long-term culture and functional characterization of follicular cells from adult normal human thyroids. ProcNatlAcadSci U S A 91: 9004-9008.

21. Longin A, Souchier C, Ffrench M (1993) Comparison of anti-fading agents used in fluorescence microscopy: image analysis and laser confocal microscopy study. J HistochemCytochem 41: 1833-1840.

22. Donnini D, Perrella G, Stel G (2000) A new model of human aortic endothelial cells in vitro. Biochimie 82:1107-1114.

23. Kimes BW, Brandt BL (1976) Properties of a clonal muscle cell line from rat heart. ExpCellRes 98: 367-381.
24. Garlanda C, Parravicini C, Sironi M (1994) Progressive growth in immunodeficient mice and host cell recruitment by mouse endothelial cells transformed by polyoma middle-sized $T$ antigen: implications for the pathogenesis of opportunistic vascular tumors. ProcNatlAcadSci U S A 91: 7291-7295.

25. Buzby JS, Knoppel EM, Cairo MS (1994) Coordinate regulation of Steel factor, its receptor (Kit), and cytoadhesion molecule (ICAM-1 and ELAM-1) mRNA expression in human vascular endothelial cells of differing origins. ExpHematol 22: 122-129.

26. Kubo H, Jaleel N, Kumarapeli A (2008) Increased cardiac myocyte progenitors in failing human hearts. Circulation 118: 649-657.

27. Matsuda R, Takahashi T, Nakamura S (1993) Expression of the c-kit protein in human solid tumors and in corresponding fetal and adult normal tissues. Am J Pathol 142: 339-346.

28. De AL, Berghella L, Coletta M (1999) Skeletal myogenic progenitors originating from embryonic dorsal aorta coexpress endothelial and myogenic markers and contribute to postnatal muscle growth and regeneration. J Cell Biol 147: 869-878.

29. Quaini F, Urbanek K, Beltrami AP (2002) Chimerism of the transplanted heart. N Engl J Med 346: 5-15.

30. Torella D, Rota M, Nurzynska D (2004) Cardiac stem cells and myocyte aging, heart failure and insuline-like growth factor-1overexpression. Circ Res: 94:514-524.

31. Barile L, Messina E, Giacomello A (2007) Endogenous cardiac stem cells ProgCardiovasc Dis 50: 31-48.

32. Niu Z, lyer D, Conway SJ (2008) Serum response factor orchestrates nascent sarcomerogenesis and silences the biomineralization gene program in the heart. ProcNatlAcadSci U S A 105: 17824-17829.

33. Tavi P, Pikkarainen S, Ronkainen J (2004) Pacing-induced calcineurin activation controls cardiac Ca2+ signalling and gene expression. J Physiol 554: 309-320.

34. Sontia B, Touyz RM (2007) Magnesium transport in hypertension. Pathophysiology 14: 205-211.

35. Simpson DG, Decker ML, Clark WA (1993) Contractile activity and cell-cell contact regulate myofibrillar organization in cultured cardiac myocytes. J Cell Biol 123: 323-336.

36. Eppenberger-Eberhardt M, Flamme I, Kurer V (1990) Reexpression of alphasmooth muscle actin isoform in cultured adult rat cardiomyocytes. DevBiol 139: 269-278.

37. Kubo H, Berretta RM, Jaleel N (2009) c-Kit+ bone marrow stem cells differentiate into functional cardiac myocytes. Clin Trans Sci2:26-32.

Copyright: (c) 2015 Francesconi A, et al. This is an open-access article distributed under the terms of the Creative Commons Attribution License, which permits unrestricted use, distribution, and reproduction in any medium, provided the original author and source are credited. 